\title{
Predictors of Perception of Risk of Contracting HIV among Migrant Road Construction Workers in Rural Cameroon
}

\section{Elvis Enowbeyang Tarkang ${ }^{1,2, *}$, Lilian Belole Pencille ${ }^{2,3}$, Flavia Adu-Poku${ }^{1}$, Seraphine Mawunya Dzah', Melanie Mbungo Nzegge ${ }^{2}$, Evans} Agamlor $^{1}$ and Seth Yao Ahiabor ${ }^{1}$

${ }^{1}$ School of Public Health, University of Health and Allied Sciences, Volta Region, Ghana

${ }^{2}$ HIVIAIDS Prevention Research Network Cameroon, Southwest Region, Cameroon

${ }^{3}$ Charlie Norwood VA Medical Center, One Freedom Way Augusta, USA

\begin{abstract}
Background: Migration, mobility, and HIVIAIDS are well-documented interlinked phenomena. While the Cameroon AIDS Strategic Plan 2014-2017 focuses on the key populations, little was mentioned on migrant workers. Nevertheless, the inclusion of migrant workers in the road construction sector in the national strategic plan offers a critical opportunity to design and deliver HIV services that meet their needs. Risk perception of HIVIAIDS should accompany risky sexual behaviour change. This study investigated the predictors of perception of risk of contracting HIV among migrant road construction workers in the Southwest region of Cameroon using the Health Belief Model (HBM) as the theoretical framework.
\end{abstract}

Methods: A cross-sectional survey of a stratified sample of 254 road construction workers was conducted at construction sites along the Kumba-Mamfe road in December 2015. Data were collected using a pretested structured questionnaire and analysed using binomial logistic regression using SPSS version 20 at the level 0.05 .

Results: Only 109 (42.9\%) perceived that they are at risk of contracting HIV. Apart from perceived susceptibility to HIV which was found to be a significant predictor of the perception of risk of contracting HIV: OR=5.12 $(95 \% \mathrm{Cl} 0.667$ $15.604, p=0.004)$, none of the other constructs of the HBM was a significant predictor of perception of risk of contracting HIV. However, the perception that HIV is deadly (perceived severity) was associated with an increased likelihood of perception of risk of contracting HIV: OR=1.23 $(95 \% \mathrm{Cl} 0.523-2.893, p=0.635)$; the perception that consistent condom use could prevent HIV transmission (perceived benefit) was associated with an increased likelihood of perception of risk of contracting HIV: OR=1.25 $(95 \% \mathrm{Cl} 0.518-3.008, p=0.621)$; the perception by workers that they could refuse sex with their partners if they refused to use condoms (perceived self-efficacy) was associated with an increased likelihood of perception of risk of contracting HIV: OR=2.04 (95\% Cl 0.888-4.693, $\mathrm{p}=0.093)$

Conclusion: There is the need for sensitization programmes and interventions to increase the perception of susceptibility to HIVIAIDS among migrant road construction workers, which will, in turn, increase their perception of risk of contracting HIV and consequently bring about sexual behaviour change.

Keywords: Perception of risk; Health belief model (HBM); HIV/ AIDS; Migrant road construction workers; Cameroon

\section{Introduction}

Migration, mobility and HIV/AIDS are well-documented interlinked phenomena. High rates of HIV infection are generally found along transport routes, in border areas, and in regions experiencing higher seasonal and long-term population mobility. In many developing countries, large infrastructure construction sites offer job opportunities that attract a large number of young people many of whom migrate from poor rural areas of nearby regions. Construction workers comprise one of the key mobile groups together with truckers, transport workers and itinerant traders [1]. Research has demonstrated a link between migration and multi-partner sexual networking as well as the prevalence of Sexually Transmitted Infections (STIs)/HIV infection [2-4].

Despite several measures that have been put in place to curb the spread of HIV/AIDS in Cameroon, available statistics shows that the scourge has continued unabated. Despite the recently reported decrease in the HIV/AIDS prevalence to $4.3 \%$ (2.9\% for men and $5.6 \%$ for women), Cameroon remains on the list of countries with the highest overall HIV prevalence in West and Central Africa [5,6].

Cameroon is facing a generalized HIV epidemic with adult prevalence varying across the different regions. The HIV epidemic in Cameroon is principally driven by high-risk heterosexual practices such as low condom use, multiple concurrent partners or a high number of lifetime sexual partners, and commercial sex activities.
The movement of people across borders and between urban and rural areas is among the factors that contribute to the rapid spread of HIV in Cameroon. At-risk populations include CSWs, MSM, long-distance truck drivers, military populations, prison populations; youth aged 15-24, orphans and vulnerable children (OVC), people with mental or physical disabilities, ethnic minorities, and migrant populations [7].

In recent years, increased investments in the road construction sector in Cameroon have increased the number of migrant workers engaged in this sector. The Cameroon National AIDS Strategic Plan 2014-2017 prioritizes prevention among the four key components in the fight against HIV/AIDS [8]. While the plan focuses on the key populations, little was mentioned on migrant workers. Nevertheless, the inclusion of migrant workers in the road construction sector in

*Corresponding author: Elvis Enowbeyang Tarkang, HIVIAIDS Prevention Research Network Cameroon, Southwest Region, Cameroon; Tel: 23777632064 E-mail: ebeyang1@yahoo.com

Received June 27, 2017; Accepted July 12, 2017; Published July 19, 2017

Citation: Tarkang EE, Pencille LB, Adu-Poku F, Dzah SM, Nzegge MM, et al (2017) Predictors of Perception of Risk of Contracting HIV among Migrant Road Construction Workers in Rural Cameroon. J AIDS Clin Res 8: 710 doi: 10.4172/21556113.1000710

Copyright: (C) 2017 Tarkang EE, et al. This is an open-access article distributed under the terms of the Creative Commons Attribution License, which permits unrestricted use, distribution, and reproduction in any medium, provided the original author and source are credited. 
the national strategic plan offers a critical opportunity to design and deliver HIV services that meet their needs. There seems to be a dearth of information on the predictors of the perception of risk of contracting HIV among migrant road construction workers in Cameroon. Therefore, it becomes necessary to carry out an empirical study of this kind in order to obtain necessary information that would aid road construction policies formulation.

The perception of being at risk of infection is one of the necessary conditions for behavioural change and the degree of perceived risk seems to affect individuals" actual control in adopting preventive measures [9]. In order for migrant road construction workers to take precautions to protect themselves against HIV infection, they first have to regard themselves as potentially at risk of becoming infected. Risk perception of HIV/AIDS should accompany risky sexual behaviour change.

Throughout literature, the Health Belief Model (HBM) has been a commonly cited theory for behaviour change that acknowledges the importance of perceived risk in behaviour change. It posits that people who perceive themselves to be at risk of a negative outcome are more likely to reduce their risk behaviours than those who do not see themselves at risk [10].

This study uses the main psychosocial constructs of the Health Belief Model (HBM) (perceived susceptibility, perceived severity, perceived benefits, perceived barriers and perceived self-efficacy) to investigate the predictors of perception of risk of contracting HIV among migrant road construction workers in a rural setting in the Southwest region of Cameroon.

The HBM postulates that health-seeking behaviour (preventing HIV/AIDS by using condoms), is influenced by a person's perception of the threats posed by a health problem (the perceived risk of contracting HIV/AIDS), and the value associated with the actions aimed at reducing the threat (consistent condom use to prevent HIV) $[11,12]$.

Based on these HBM assumptions, it could be concluded that without migrant workers' perceptions of HIV/AIDS being a threat, there could be no resultant preventative actions against HIV/AIDS (using condoms effectively). Therefore, the perceived risk of contracting HIV/AIDS is assumed to be the immediate antecedent of the consistent use of condoms to prevent HIV/AIDS. It is, therefore, hypothesised that the higher a worker's perceived risk of contracting HIV/AIDS, the higher his chances of implementing preventive measures. Therefore, the perception of risk is explained by the components of the HBM.

\section{Methods}

\section{Research design}

A cross-sectional survey was conducted among 254 migrant road construction workers at construction sites along the Kumba-Mamfe road in the Southwest region of Cameroon in December 2015. Data were collected using a pretested structured questionnaire.

\section{Study setting}

The study was conducted at the two construction sites along the Kumba-Mamfe road in the Southwest region of Cameroon. This road passes through five municipalities in the Southwest region of Cameroon: Kumba III, Konye, Nguti, Tinto and Mamfe municipalities, covering a considerable expanse of land. The Southwest region has an HIV/AIDS prevalence of 5.7\%, which is above the Cameroon national prevalence of $4.3 \%$ [5].

\section{Study population}

The population for this study comprised male construction workers at the two road construction sites along the Kumba-Mamfe road in the Southwest region of Cameroon made up of Drivers, Builders, Welders, Iron Benders and Unskilled Laborers.

\section{Sampling method}

A proportionate stratified sampling approach was used whereby for each construction site, a list of all employees was obtained along with their types of work. The research team then attempted to sample a proportionate number of employees from each site in order to make up the predetermined sample size for each construction site. Workers of the HIV/AIDS Prevention Research Network, Cameroon (HIVPREC), acting as peer educators explained to the workers what the survey was all about. Those who were interested consented to participate.

\section{Data collection}

A pre-tested structured questionnaire was used to collect data for this study. The questionnaire was pretested on a convenience sample of 10 migrant road construction workers who did not take part in the actual study. The questionnaires were administered by trained facilitators of HIVPREC, due to the perceived low level of literacy of the respondents. The validity of the questioned was ensured by designing items to measure the different variables of the study by the first author who is a specialist in HIV research. The questionnaire captured data on socio-demographic characteristics (age, marital status, religion, educational level and profession), constructs of the HBM (perceived susceptibility to HIV, perceived severity of HIV, perceived benefits of condom use, perceived barriers to condom use, perceived selfefficacy for condom use and perception of risk of contracting HIV). Previous studies guided the development of the questionnaires $[13,14]$. Completed questionnaires were checked by the HIVPREC facilitators, to ensure the completeness and consistency of the data.

\section{Ethical considerations}

Respondents were given verbal and written information about the study and signed an informed consent form before participation in the study. No personal or identifying information was retained in the questionnaire. All respondents participated on a voluntary basis and no financial incentives were provided. Permission to conduct this study was obtained from research and ethics committee of the HIV/ AIDS Prevention Research Network, Cameroon (HIVPREC) and from the Management of the Kumba-Mamfe road project in the Southwest region of Cameroon. Ethical clearance for this study was obtained from the research and ethics committee of the faculty of philosophy, religious and social studies of the Cameroon Christian University (CCU).

\section{Measures}

\section{Outcome (dependent) variable: perception of risk of contracting HIV}

- Perception of risk of contracting HIV: This was measured with the following question: 'How at risk of contracting HIV are you?' The response options were ' $1=$ not at risk' (reference category)' and ' $2=$ at risk'.

\section{Predictor (independent) variables: Constructs of the HBM}

- Perceived susceptibility to HIV: This was measured based on the level of agreement with the following item: 'Road construction workers are prone to HIV/AIDS. The response options were 
categorized into '2=agree' and ' $1=$ disagree'. 'Disagree' was coded as the index category.

- Perceived severity of HIV/AIDS: This measure was based on the degree of agreement with the following statement: 'HIV/AIDS is a deadly disease. The response options were the same as for 'perceived susceptibility' and were coded in the same manner.

- Perceived benefit of condom use: This was measured based on the level of agreement with the following item: 'Consistent condom use during sexual intercourse can prevent HIV transmission'. The response options were the same as for 'perceived severity' and were coded in like manner.

- Perceived barriers to condom use: This measure was based on the degree of agreement with each of the following statements: 'I feel embarrassed to buy condoms', 'I lack knowledge on correct condom use' and 'Condom use decreases sexual pleasure. The response options were the same as for 'perceived benefit' and were coded in like manner.

- Perceived self-efficacy for condom use: This measure was based on the degree of agreement with the following statement: 'I feel confident to refuse sex with my partner(s) if they refuse to use condom. The response options were the same as for 'perceived barriers' and were coded in like manner.

- Socio-demographic variables: The following socio-demographic variables were included in the study: age, categorized into five groups (10-19, 20-29, 30-39, 40-49 and 50 and above years), marital status, categorized into three groups (single, married and others), Religion, categorized into three groups (Christian, Muslim and others), Educational level categorized into four groups (No education, primary, secondary/high school and tertiary) and occupation, categorized into Driving, Building, Iron Bending, Welding and Unskilled labour.

\section{Data analysis}

Frequencies, percentages, and binomial logistic regression were performed using SPSS version 20 software program at the level 0.05 , to examine the likelihood of perception of risk of contracting HIV.

Binomial logistic regression predicts the probability that an observation falls into one of two categories of a dichotomous dependent variable based on one or more independent variables that can be either continuous or categorical. The procedure gives rise to estimates of odds of a certain event occurring (perception of risk of contracting HIV), given a set of explanatory variables (the main psychosocial constructs of the HBM and the socio-demographic factors).

To estimate the odds ratios (OR), we built different models predicting the perception of risk of contracting HIV, using the main constructs of the HBM and the socio-demographic factors. To assess the predictive utility of each construct of the HBM as a whole model, that is how individuals with various combinations of health beliefs are more or less likely to perceive themselves at risk of contracting HIV; each component of the HBM was entered into the model one at a time. The significant level for all statistical tests was $5 \%$.

\section{Results}

\section{Socio-demographic characteristics}

The majority of the respondents, 219 (86.2\%) were aged $20-49$ years; most, 212 (83.5\%) were Christians; most, 186 (73.2\%) were single and the majority, $170(66.9 \%)$ had up to high school level of education (Table 1).

\section{Descriptive statistics (Constructs of the health belief model)}

The perception by the road construction workers that they are prone to HIV (perceived susceptibility) was high, 203 (79.9\%). A slight majority, $163(64.2 \%)$ perceived that HIV/AIDS is deadly (perceived severity) and a slight majority, 159 (62.6\%) also perceived that consistent condom use could prevent HIV transmission (perceived benefit). Only 137 (53.9\%) perceived that they could refuse sex with their partners if they refused to use condoms (perceived self-efficacy). However, 108 (42.5\%) perceived that they feel embarrassed to buy condoms, 135 (53.1\%) perceived that they lack knowledge about correct condom usage and $162(63.8 \%)$ perceived that condom use decreases sexual pleasure (perceived barriers) and only 109 (42.9\%) perceived that they are at risk of contracting HIV (Table 2).

\begin{tabular}{|c|c|c|}
\hline Characteristics & Frequency & Percentage \\
\hline $\begin{array}{ll}- & \text { Age Group } \\
- & 10-19 \\
- & 20-29 \\
- & 30-39 \\
- & 40-49 \\
- & 50 \text { and above }\end{array}$ & $\begin{array}{c}19 \\
106 \\
74 \\
39 \\
16\end{array}$ & $\begin{array}{c}7.5 \\
41.7 \\
29.1 \\
15.4 \\
6.3\end{array}$ \\
\hline $\begin{array}{ll}- & \text { Religious Affiliation } \\
- & \text { Christian } \\
- & \text { Muslim } \\
- & \text { Others }\end{array}$ & $\begin{array}{c}212 \\
27 \\
15\end{array}$ & $\begin{array}{c}83.5 \\
10.6 \\
5.9\end{array}$ \\
\hline $\begin{array}{ll}- & \text { Marital Status } \\
- & \text { Single } \\
- & \text { Married } \\
- & \text { Others }\end{array}$ & $\begin{array}{c}186 \\
47 \\
21\end{array}$ & $\begin{array}{c}73.2 \\
18.5 \\
8.3\end{array}$ \\
\hline $\begin{array}{ll}- & \text { Educational Attainment } \\
- & \text { No education } \\
- & \text { Primary } \\
- & \text { Secondary/High school } \\
- & \text { Tertiary } \\
\text { - } & \text { Occupation } \\
- & \text { Driving } \\
- & \text { Building } \\
- & \text { Iron bending } \\
- & \text { Welding } \\
- & \text { Unskilled labour }\end{array}$ & $\begin{array}{c}81 \\
92 \\
78 \\
3 \\
\\
16 \\
70 \\
55 \\
43 \\
70\end{array}$ & $\begin{array}{c}31.9 \\
36.2 \\
30.7 \\
1.2 \\
\\
6.3 \\
27.6 \\
21.6 \\
16.9 \\
27.6\end{array}$ \\
\hline
\end{tabular}

Table 1: Socio-demographic characteristics of the study population.

\begin{tabular}{|c|c|c|}
\hline Predictors & Frequency & Percentage \\
\hline \multirow{2}{*}{\multicolumn{3}{|c|}{$\begin{array}{l}\text { Road construction workers are prone to HIV } \\
\text { - Agree } \\
\text { HIVIAIDS is a deadly disease }\end{array}$}} \\
\hline & & \\
\hline - Agree & 163 & 64.2 \\
\hline - Disagree & 91 & 35.8 \\
\hline \multicolumn{3}{|l|}{ Consistent condom use can prevent HIV transmission } \\
\hline - Disagree & 95 & 62 \\
\hline \multicolumn{3}{|l|}{ I feel embarrassed to buy condoms } \\
\hline - Agree & 108 & 42.5 \\
\hline - Disagree & 146 & 57.5 \\
\hline \multicolumn{3}{|l|}{ I lack knowledge on correct condom use } \\
\hline - Agree & 135 & 53.1 \\
\hline - Disagree & 119 & 46.9 \\
\hline \multicolumn{3}{|l|}{ Condom use decreases sexual pleasure } \\
\hline - Agree & 162 & 63.8 \\
\hline - Disagree & 92 & 36.2 \\
\hline \multicolumn{3}{|l|}{$\begin{array}{l}\text { I feel confident to refuse sex with my partner(s) if they } \\
\text { refuse to use condoms }\end{array}$} \\
\hline - Agree & 137 & 53.9 \\
\hline - Disagree & 117 & 46.1 \\
\hline \multicolumn{3}{|l|}{ Perception of risk of contracting HIV } \\
\hline - At $r$ & & \\
\hline - Not at risk & 145 & 57.1 \\
\hline
\end{tabular}

Table 2: Predictors of perception of risk of contracting HIV. 
Citation: Tarkang EE, Pencille LB, Adu-Poku F, Dzah SM, Nzegge MM, et al. (2017) Predictors of Perception of Risk of Contracting HIV among Migrant Road Construction Workers in Rural Cameroon. J AIDS Clin Res 8: 710. doi: 10.4172/2155-6113.1000710

Page 4 of 6

\section{Predictors of perception of risk of contracting HIV}

The model explained 33\% (Nagelkerke $\mathrm{R}^{2}$ ) of the variance in the perception of risk of contracting HIV and correctly classified about $73 \%$ of cases in the sample into workers with low and high perception of risk of contracting HIV. The logistic regression model (Chi-square) was statistically significant $(\mathrm{p}=0.026)$ denoting adequate explanatory powers of the variables used in explaining the dependent variable.

The level of significance of the various HBM constructs is explained by the p-values of the Chi-square statistics. Therefore, apart from perceived susceptibility to HIV which was found to be a significant predictor of the perception of risk of contracting HIV among the migrant road construction workers in Rural Cameroon: $\mathrm{OR}=5.12$ (95\% CI 0.667-15.604, $\mathrm{p}=0.004$ ), none of the other constructs of the HBM was a significant predictor of perception of risk of contracting HIV. However, the perception that HIV is deadly (perceived severity) was associated with an increased likelihood of perception of risk of contracting HIV, OR=1.23 (95\% CI 0.523-2.893, $\mathrm{p}=0.635)$; the perception that consistent condom use could prevent HIV transmission (perceived benefit) was associated with an increased likelihood of perception of risk of contracting HIV, OR=1.25 (95\% CI 0.518-3.008, $\mathrm{p}=0.621$ ); the perception by workers that they could refuse sex with their partners if they refused to use condoms (perceived self-efficacy) was associated with an increased likelihood of perception of risk of contracting HIV, OR=2.04 (95\% CI 0.888-4.693, p=0.093). In the same vein, the perception that condom use reduces sexual pleasure (perceived barrier), was associated with an increased likelihood of perception of risk of contracting HIV: OR=1.20 (95\% CI 0.489-2.784, $\mathrm{p}=0.120)$ (Table 3).

\section{Discussion}

From the literature review, it is evident that the current study is the first in Cameroon to report on the predictors of perception of risk of contracting HIV among migrant road construction workers in rural Cameroon, using the HBM as the conceptual framework.

As revealed in Table 2, only $42.9 \%$ of the migrant road construction workers perceived that they were at risk of contracting HIV. This is in accordance with previous findings among High school students in
Cameroon, 42.5\% [13], but slightly above previous studies conducted among female students in rural Cameroon, 39.4\% [14]. The observed discrepancies could be explained by the differences in the sexual activities between males and females in the two studies. The current study was conducted among male road construction workers, while the 2014 study was among female high school students.

The finding of low perception of risk was also in accordance with other studies conducted among migrant road construction workers in China, where the majority perceived that they were not at risk of contracting HIV [15]. A high level of health risk awareness is very useful to increase the perceptual vigilance on HIV, which can improve utilization of health service, and decrease HIV risk [16].

This study revealed that perceived susceptibility to HIV was the only significant predictor of HIV risk perception. This is in contrast with previous findings among female high school students in rural Cameroon, where none of the components of the HBM was a significant predictor of HIV risk perception [14]. This difference could be explained by the fact that in the 2014 study, the students were more aware of their susceptibility to HIV maybe through health education in school than the migrant workers in the current study, most of whom are school dropped-out.

It can be seen from Table 3 that perceived susceptibility contributed significantly to the model $(\mathrm{p}=0.004)$. Workers with a high perception of susceptibility to HIV were 5 times more likely to perceive themselves at risk of contracting HIV. This finding, therefore, showed that perceived susceptibility to HIV was a significant predictor of perception of risk of contracting HIV among migrant road construction workers in rural Cameroon. The possible explanation for this outcome could be that the majority of the workers, 203 (79.9\%) perceived that they are prone to HIV.

Several factors could determine the perception of susceptibility to HIV, including sexual risk behaviours and knowledge regarding HIV/ AIDS [17]. Migrant road construction workers may lack adequate knowledge regarding HIV due to their low levels of education or may be indulging in sexual risk behaviours, which might increase their susceptibility to HIV. Therefore, perceived susceptibility being a significant predictor of perception of risk of contracting HIV, should be

\begin{tabular}{|c|c|c|c|c|}
\hline Effect & Odds Ratios (OR) & Confidence interval (Cl) & Wald & $P$ value \\
\hline \multicolumn{5}{|l|}{ Perceived Susceptibility to HIV } \\
\hline - Road construction workers are prone to HIVIAIDS & 5.12 & $(0.667-15.604)$ & 8.232 & 0.004 \\
\hline \multicolumn{5}{|l|}{ Perceived severity of HIVIAIDS } \\
\hline - HIVIAIDS is a serious and deadly disease & 1.23 & $(0.523-2.893)$ & 0.225 & 0.635 \\
\hline \multicolumn{5}{|l|}{ Perceived benefit of condom use } \\
\hline - Consistent condom use can prevent the sexual transmission of HIV & 1.25 & $(0.518-3.008)$ & 0.245 & 0.621 \\
\hline \multicolumn{5}{|l|}{ Perceived barriers to condom use } \\
\hline - I feel embarrassed to buy condoms & 1.40 & $(0.592-3.295)$ & 0.584 & 0.445 \\
\hline - I lack knowledge on correct use of condoms & 1.34 & $(0.559-3.214)$ & 0.432 & 0.551 \\
\hline - Condoms reduce sexual pleasure & 1.20 & $(0.489-2.784)$ & 0.729 & 0.120 \\
\hline \multicolumn{5}{|l|}{ Perceived condom use self-efficacy } \\
\hline - I feel confident that I can refuse sex with my partner(s) if they refuse to use condoms & 2.04 & $(0.888-4.698)$ & 2.828 & 0.093 \\
\hline \multicolumn{5}{|l|}{ Perception of risk of contracting HIV } \\
\hline - How at risk of contracting HIV are you & 1.004 & $(0.527-1.910)$ & 0.000 & 0.991 \\
\hline Age & 10.12 & $(0.517-33.385)$ & 2.327 & 0.127 \\
\hline Religion & 2.04 & $(0.857-16.115)$ & 1.056 & 0.501 \\
\hline Occupation & 1.75 & $(0.142-21.495)$ & 0.191 & 0.662 \\
\hline Marital status & 2.7 & $(0.292-25.924)$ & 0.781 & 0.377 \\
\hline
\end{tabular}

Table 3: Odds Ratios (OR) of perception of risk of contracting HIV from the logistic regression models. 
the main area of focus in programmes aimed at increasing the perception of risk of contracting HIV among migrant road construction workers in rural Cameroon. When migrant road construction workers perceive themselves to be susceptible to HIV, they will be more likely to take measures to prevent the disease either by using condoms consistently or by abstaining from sexual intercourse. This finding implies the need for migrant road construction workers to be educated and sensitised on the risk factors for HIV transmission such as sexual risk behaviours.

The finding regarding perceived susceptibility highlights the importance of the HBM in explaining the perception of risk of contracting HIV. This finding is consistent with the HBM that perceived susceptibility could lead to preventative behaviours [10-12].

Table 3 shows that perceived severity of HIV was not a significant predictor of perception of risk of contracting HIV $(p=0.635)$. The possible explanation could be that the migrant road construction workers may not have perceived HIV/AIDS to detrimental to their lives; only 163 (64.2\%) perceived that HIV/AIDS is deadly. It could be assumed that workers with low perceived severity of HIV may not be knowledgeable about the fact that HIV/AIDS is deadly and contracting HIV may have serious consequences on the individual. Therefore, the perceived severity of HIV/AIDS may enable migrant workers to evaluate the seriousness and complications associated with the disease and to take appropriate decisions about prevention. Despite the seriousness of HIV/AIDS, this study found no significant relationship between perceived severity and perception of risk of contracting HIV. This notwithstanding, public health education on HIV prevention should highlight the seriousness of the disease as it could potentially enhance the perception of risk of contracting the disease, which in turn may lead to the adoption of preventive measures.

As can be seen in Table 3, perceived barrier to condom use was also not a significant predictor of perception of risk of contracting HIV $(\mathrm{p}=0.120)$. This could be explained by the fact that in this study, only a slight majority of the migrant road construction workers, $63.8 \%$, perceived that condom use decreases sexual pleasure. According to the HBM, perceived barriers to condom use should act as impediments to the perception of risk of contracting HIV $[18,19]$.

Table 3 also showed that perceived benefit of condom use was not a significant predictor of perception of risk of contracting HIV $(\mathrm{p}=0.621)$. The possible explanation of this could be that only a slight majority of the migrant workers, $62.6 \%$ perceived that consistent condom use during sexual intercourse can prevent HIV transmission. Going by the level of sensitization that has taken place worldwide and in Cameroon [8], one would have expected that the perceived benefit of condom use to prevent HIV should be near $100 \%$. This finding calls for concerted efforts by stakeholders to implement strategies to sensitise road construction workers on the benefit of condom use to prevent HIV transmission.

Table 3 also showed that perceived condom use self-efficacy was not a significant predictor of perception of risk of contracting HIV $(\mathrm{p}=0.93)$. This finding could be explained by the fact that in this study, only a slight majority, $53.9 \%$ perceived that they had the confidence to refuse sex with their partners if they refused to use condoms. This, however, calls for strategies to increase the condom use self-efficacy among migrant road construction workers in Cameroon, in order to increase their perception of risk of contracting HIV.

According to the HBM, without the perception of risk of contracting HIV, there would be no resultant use of condom consistently to prevent it $[11,12]$. The current study had some limitations. First, the road construction workers who are all youths may exhibit optimistic bias, tending to underestimate risks in general due to feelings of invulnerability. Additionally, HIV/AIDS is a highly stigmatised disease. Acknowledging one's own risk implies putting oneself at risk of being stigmatised. Thus, they may avoid self-disclosure, this by downplaying their own personal risk, which leads to further low-risk perceptions. Secondly, because of the cross-sectional nature of the data, most responses were evaluated retrospectively and recall bias was therefore unavoidable. Thirdly, because of the small sample size, the findings may not be generalised to the entire country. A different result might have been obtained if a larger sample was used.

\section{Conclusion}

The results of the current study show that migrant road construction workers in rural Cameroon perceive themselves not at risk of contracting HIV, with those who perceive that they are prone to HIV, more likely to perceive themselves at risk of contracting the disease. These findings show that there is the need for sensitization programmes regarding HIV/AIDS transmission and prevention, targeted at migrant road construction workers in Cameroon. These programmes and interventions could increase their perception of susceptibility to HIV/ AIDS, which will, in turn, increase their perception of risk of contracting $\mathrm{HIV}$ and consequently bring about sexual behaviour change.

\section{Acknowledgement}

We acknowledge the workers of the HIVIAIDS Prevention Research Network Cameroon (HIVPREC) for collecting the data for this study.

\section{Authors' Contributions}

EET conceived the study, did the data analysis and wrote the initial draft of the manuscript. EET, LBP, SMD, FA, MMN and SYA revised the manuscript. All the authors reviewed and approved the final version of the manuscript.

\section{References}

1. Asian Development Bank (2003) Preventing HIVIAIDS on road projects in Yunnan Province, China.

2. Saggurti N, Verma RK, Jain A, RamaRao S, Kumar KA, et al. (2008) HIV risk behaviors among contracted and non-contracted male workers in India Potential role of contractors and contractual system in HIV prevention. AIDS 22: $127-136$.

3. UNESCO, UNAIDS (2000) Migrant population and HIVIAIDS: The development and implementation of programs: Theory and methodology and practice. UNESCO/UNAIDS.

4. Gurung G (2004) An overview paper on overseas employment in Nepal. International Labour Organization: Kathmandu, Nepal.

5. Cameroon National Institute of Statistics, ICF International (2012) Demographic and health survey and multiple indicators cluster surveys 2011. INS and ICF International, Calverton, Maryland, USA.

6. Pepfar (2013) Cameroon operational plan report. FY

7. Pepfar (2012) Cameroon operational plan report. FY Cameroon.

8. UNAIDS (2014) 2012-2015 Unified budget, results and accountability framework country case studies: Cameroon, Guatemala, Indonesia, Islamic Republic of Iran, Jamaica and Ukraine. UNAIDS, Geneva, Switzerland.

9. Bernardi L (2002) Determinants of individual AIDS risk perception: Knowledge behavioural control, and social influence. Afr J AIDS Res 1: 111-124.

10. Stout AE (1997) Prenatal care for low-income women and the health belie model: A new beginning. J Commun Health Nurs 4: 169-180.

11. Bartholomew LK, Parcel G, Kok G, Gottlieb NH (2006) Behavior oriented theories used in health promotion. Planning Health Promotion Programs, Jossey-Bass, San Francisco.

12. University of Twente (2010) Health Belief Model. Unpublished online information, Netherlands. 
Citation: Tarkang EE, Pencille LB, Adu-Poku F, Dzah SM, Nzegge MM, et al. (2017) Predictors of Perception of Risk of Contracting HIV among Migrant Road Construction Workers in Rural Cameroon. J AIDS Clin Res 8: 710. doi: 10.4172/2155-6113.1000710

Page 6 of 6

13. Tarkang EE, Van der Wal DM, Ehlers VJ (2011) The explanatory power of factors associated with the perceived risk of contracting HIV among senior secondary school learners in Kumba, Cameroon. Africa J Nurs Midwifery 13: 77-91.

14. Tarkang EE (2014) Factors associated with perception of risk of contracting HIV among secondary school female learners in Mbonge subdivision of rural Cameroon. Pan Afr Med J 17: 259.

15. Li L, Morrow M, Kermode M (2010) Rural-to-urban male migrant workers' vulnerability to HIV infection in Chengdu, China: Qualitative findings from a mixed-method study. Work 37: 375-386.

16. Shi Y, Ji Y, Sun J, Wang Y, Sun X, et al. (2012) Lack of health risk awareness in low-income Chinese youth migrants: Assessment and associated factors. Environ Health Prev Med 17: 385-393.

17. Renne E (1997) Local institutional interpretations of IUDS in South-Western Nigeria. Soc Sci Med 44: 1141-1148.

18. Resource Centre for Adolescent Pregnancy Prevention (2005) Theories and approaches: Health Belief Model.

19. Groenewold G, Bruijn B, Bilsborrow R (2006) Migration of the Health Belief Model (HBM): Effects of psychology and migrant network characteristics on emigration intentions on five countries in West Africa and the Mediterranean region. Population Association of America annual meeting. 